\title{
Evaluation of the Lundh test in the diagnosis of pancreatic disease
}

\author{
G. E. LEVIN, G. R. YOUNGS, AND I. A. D. BOUCHIER \\ From the Departments of Chemical Pathology and Medicine, the Royal Free Hospital, London
}

SYNOPSIS The Lundh test meal was administered to 32 normal subjects and 53 patients with suspected pancreatic disease. Tryptic activity was measured in the recovered duodenal juice. The level of activity distinguished the normal subjects from those with independently confirmed pancreatic disease, particularly chronic pancreatitis and carcinoma of the pancreas. The advantages and disadvantages of the test are discussed.

The investigation of pancreatic disease by assessment of exocrine function of the gland has been carried out largely by studies in which the duodenum is intubated and the pancreatic secretions collected in response to a standard stimulus. The stimuli commonly used are intravenous secretin, intravenous pancreozymin, and a test meal. The value of hormonal stimuli has been well documented(Dreiling, 1970), but there have been relatively few reports assessing the value of a test meal as a stimulus to pancreatic exocrine function. The use of a test meal was described by Lundh $(1962,1965)$ and further assessed by Cook, Lennard-Jones, Sherif, and Wiggins (1967). Its use was briefly documented by Ventske, Davidson, and Grossman (1964) and by Zieve, Mulford, and McHale (1966) who investigated only normal subjects, and by McCarthy and Brown (1969) who compared the diagnostic value of the Lundh test with pancreatic scintiscanning. In these reports, including the present study, duodenal trypsin levels were used as an index of pancreatic function. In this work we present further data on the diagnostic value of the Lundh test in a group of patients with pancreatic disease.

\section{Subjects and Methods}

A total of 85 patients was investigated by this technique. Thirty-two were classified as normal and were either healthy volunteers (7) whose consent had been obtained or patients (25) admitted for the investigation of abdominal pain for which no cause was subsequently found. Subjects were allocated to the various diagnostic groups after clinical assess-

Received for publication 28 July 1971. ment, barium meal, pancreatic selenomethionine scintiscan, and standard biochemical investigations. Seventeen patients had pancreatic carcinoma, 15 proven at laparotomy or at necropsy. Eleven patients had chronic pancreatitis, demonstrated at laparotomy in six patients and by pancreatic calcification in three. Seven patients had bile duct obstruction, which was shown at laparotomy to be due to a bile duct carcinoma in four subjects, duodenal carcinoma involving the bile duct in one, and to an ampullary stone in two. Three patients had haemochromatosis proven by histological and biochemical evidence of increased body iron stores. Fifteen patients did not fall into the above categories and were allocated to a 'miscellaneous' group.

Pancreatic function was measured after stimulation with a Lundh test meal (Lundh, 1962; Cook et $a l, 1967)$ consisting of $18 \mathrm{~g}$ of corn oil, $15 \mathrm{~g}$ of casilan, and $40 \mathrm{~g}$ of glucose made up to $300 \mathrm{ml}$ with water. The patient was given metoclopramide $10 \mathrm{mg}$ orally immediately before intubation to promote gastric motility and to prevent nausea. The test was carried out on the fasting subject intubated through the nose with a 12 French gauge Levin tube. A mercury bag was attached to the end of a tube which was screened under $x$-ray control to lie at or just beyond the duodenal-jejunal flexure. The subject then drank the test meal and the duodenal contents were collected by continuous siphonage and intermittent aspiration for up to 150 minutes in four or five consecutive 30-minute periods. When the aspirate was bile-free or acidic further $x$-ray screening was carried out to check whether the tube had been displaced. The duodenal aspirate was collected on ice and stored at $-20^{\circ} \mathrm{C}$. 


\section{Measurement of Tryptic Activity}

Trypsin was assayed by measuring the rate of hydrolysis of $p$-toluene-sulphonyl-L-argenine methyl ester (TAME) based on the method of Hummel (1959). The final test cuvette composition was: $2.6 \mathrm{ml}$

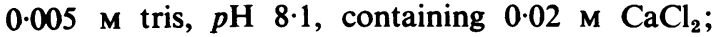
$0.3 \mathrm{ml} \mathrm{0.01} \mathrm{M} \mathrm{TAME;} 0.09 \mathrm{ml} 0.001 \mathrm{M} \mathrm{HCl}$; and $0.01 \mathrm{ml}$ duodenal aspirate. The composition of the blank cuvette was identical except that in place of the aspirate a further $0.01 \mathrm{ml}$ of $\mathrm{HCl}$ was added. The absorbency changes were monitored at $247 \mathrm{~nm}$ at room temperature which was shown to be between 21 and $23^{\circ} \mathrm{C}$. The reaction was started by the addition of undiluted duodenal aspirate and results were expressed as $\mu \mathrm{mol}$ TAME hydrolysed per millilitre aspirate per minute. The activity of a partially purified bovine pancreatic trypsin (Sigma) was measured before each group of assays.

The precision of the assay calculated from replicate determinations was found to be $3 \%$. An index of the batch-to-batch precision was obtained by measuring the activity of the commercial trypsin preparation before each group of assays. The coefficient of variation for these assays was found to be $13 \%$. Assays of samples stored at $-20^{\circ} \mathrm{C}$ for up to three months showed no significant loss of tryptic activity during this period.

\section{Results}

The results for the normal subjects are summarized in Figure 1.

Tryptic activities for each 30-minute fraction are plotted individually, and in addition activities are expressed as a mean of the entire two-hour collection period (mean tryptic activity) or as the highest activity attained in any one 30 -minute collection (peak tryptic activity). When frequency distribution curves for all fractions were constructed it was noted that the results were log normal. Hence the ranges (mean $\pm 2 \mathrm{SD}$ ) finally used in this study are derived from the log normal data for the mean and peak tryptic activities.

It can be seen that there is a general pattern of tryptic activities, the highest levels being found in the first and last 30-minute fractions. (In 11 subjects a fifth 30-minute fraction was measured. The mean activity was found to be $69 \mu \mathrm{mol} / \mathrm{ml} / \mathrm{min}$.) The results show that the mean tryptic activity for the two-hour collection period is the least variable of the analyses presented, the normal range being $27.80 \mu \mathrm{mol} / \mathrm{ml} /$ min at $22^{\circ} \mathrm{C}$. The normal range for the peak tryptic activity was found to be $33-117 \mu \mathrm{mol} / \mathrm{ml} / \mathrm{min}$ at $22^{\circ} \mathrm{C}$. Analysis of the results on the basis of volumes of aspirate recovered and total activity in the aspir-

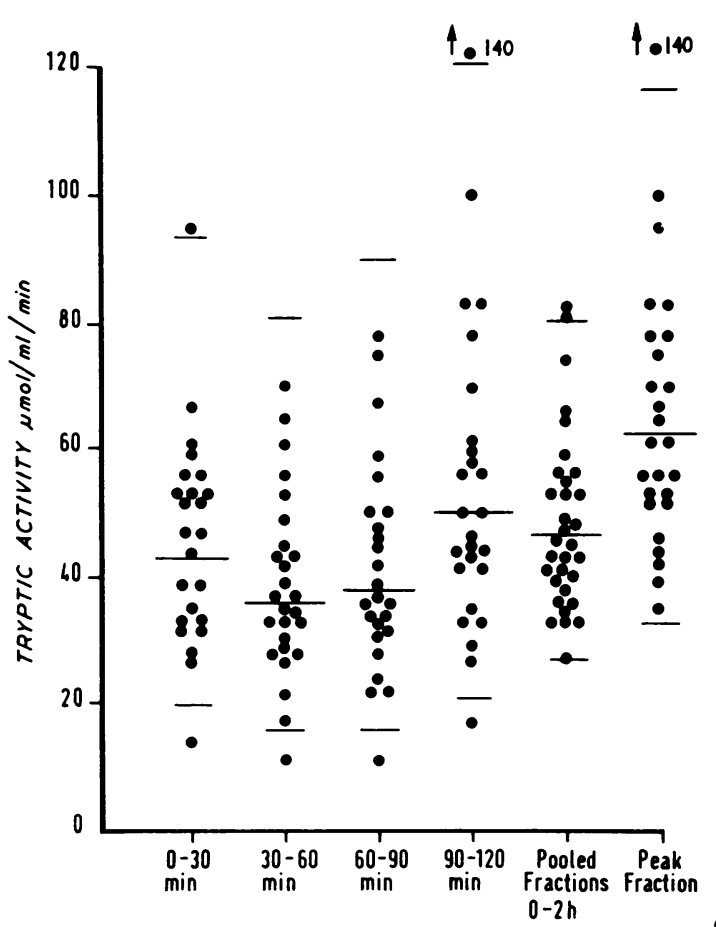

Fig. 1 Tryptic activities in the various fractions obtained for 32 normal subjects. Log mean values $\pm 2 S D$ are indicated.

ated juice gave results too variable to be of any value in discriminating between the normal and abnormal pancreas.

The results in the patients with pancreatic disease are summarized in Figures 2 and 3. Of the 17 patients with carcinoma of the pancreas, 13 showed a mean tryptic activity below the normal range. The remaining patients had obstructive jaundice, due to a carcinoma in the head of the pancreas in three, and to a sarcoma involving the head of the pancreas in a fourth. In three of these patients surviving pancreatic tissue was seen on the pancreatic scan. All the patients shown to have chronic pancreatitis gave mean two-hour tryptic activities at or below the normal range. The seven patients with bile duct obstruction gave activities within the normal range and the pancreases of these patients were shown to be normal at laparotomy. Two patients with adequately treated haemochromatosis, one with and one without cirrhosis, showed normal tryptic activities. The third patient, also cirrhotic, showed a subnormal mean two-hour trypsin value of 16 $\mu \mathrm{mol} / \mathrm{ml} / \mathrm{min}$ which, on repeating the Lundh test nine months later after treatment had been instituted, rose to a value of $32 \mu \mathrm{mol} / \mathrm{ml} / \mathrm{min}$. 


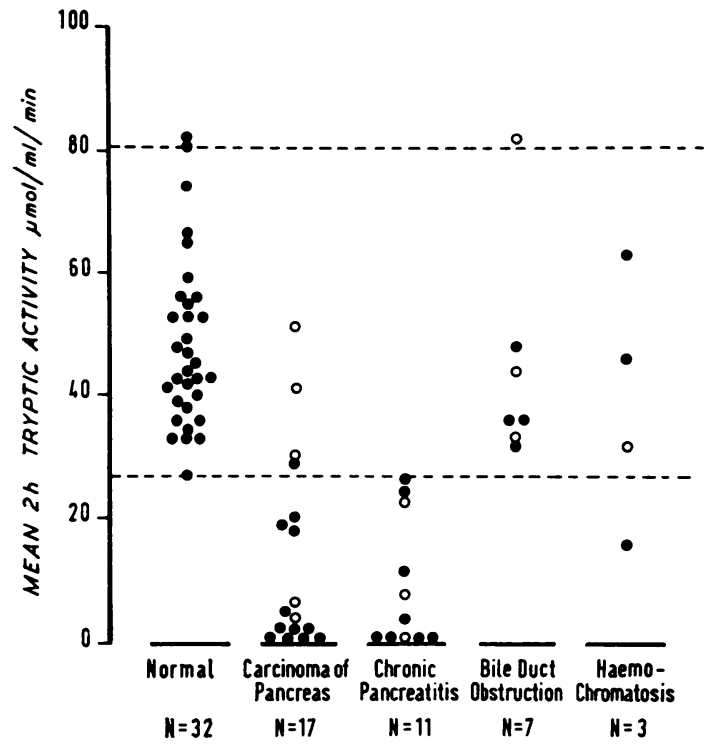

Fig. 2 Mean tryptic activities in the various diagnostic groups. The log normal range is indicated by the broken lines. : both mean and peak tryptic activities estimated; $\bigcirc$ : only mean tryptic activities estimated.

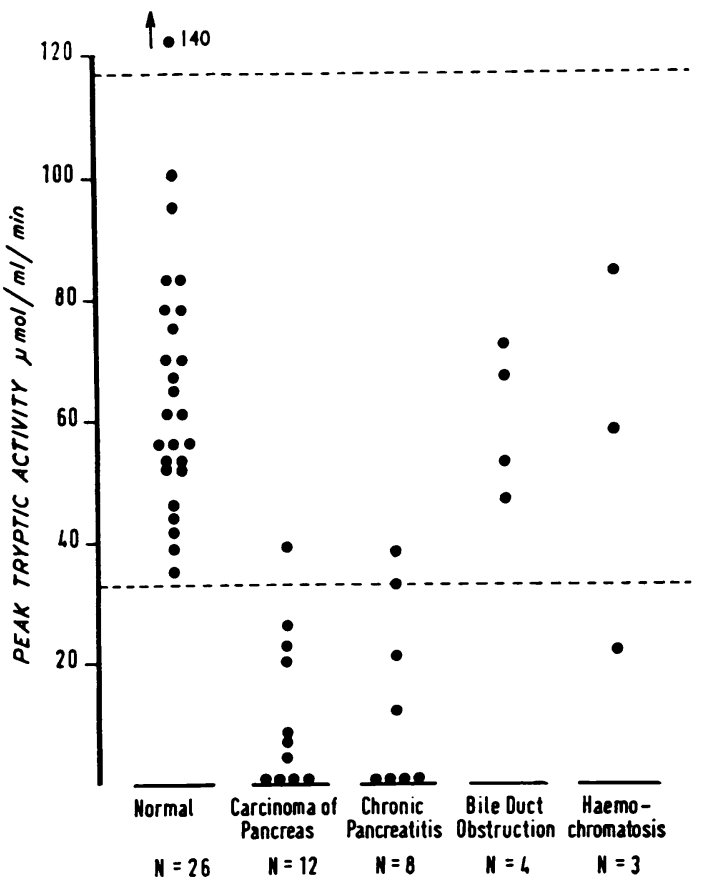

Fig. 3 Peak tryptic activities obtained in the various diagnostic groups. The log normal range is indicated by the broken lines.
Discussion

In this study we found the mean and peak tryptic activity about equally discriminatory in separating the normal group from those patients with pancreatic disease (Figs. 2 and 3). As the mean tryptic activity requires only a single assay, and the peak activity, four, the former estimation has been used throughout to express the results.

In general the Lundh test distinguishes the normal subjects from those patients with chronic pancreatitis and carcinoma of the pancreas, although two out of 17 patients with carcinoma of the pancreas, both of whom had obstructive jaundice, gave levels of activity within the normal range. A further two patients gave results on the lower limit of the normal range. The two patients with carcinoma of the body of the pancreas were not jaundiced and gave results below the normal range. The seven patients with bile duct obstruction also gave results within the normal range. Thus in the presence of obstructive jaundice a normal Lundh test is suggestive but not diagnostic of an extrapancreatic lesion, and in this situation a pancreatic scan may be helpful or even more reliable (Youngs, Agnew, Levin, and Bouchier, 1971).

The test alone is of no value in distinguishing between chronic pancreatitis and carcinoma of the pancreas, and in this respect may be less discriminatory than a secretin-pancreozymin test, which occasionally provides differentiation (Dreiling and Janowitz, 1962).

Of the six patients with proven chronic pancreatitis where steatorrhoea was a prominant feature, five gave zero tryptic activity in the duodenal aspirates. One patient gave a level of $12 \mu \mathrm{mol} / \mathrm{ml} / \mathrm{min}$. These results confirm the observation (Cook et al, 1967) that pancreatic disease has to be extensive before steatorrhoea occurs.

Six patients studied initially did not receive metaclopramide and in four of these the test failed because of vomiting. For this reason, the remaining patients in the study received the drug before intubation, and subsequently only one patient vomited. In only eight of the 87 patients who received metoclopramide, was the test a technical failure because the tube failed to pass the pylorus ( 5 patients), or because the tube regurgitated into the stomach ( 3 patients). The technical failure rate was thus about $10 \%$. The secretin-pancreozymin test involves the passage of a large double-lumen tube which is more traumatic to the patient and which may cause retching. Meticulous collections of duodenal juice are necessary and intravenous pancreozymin may cause hypersensitivity reactions and abdominal colic. As tryptic activity, and not 
total output, are measured for the Lundh test, complete collection of the aspirate is unnecessary.

The advantages of the Lundh test are that it measures pancreatic enzyme output in response to the physiological stimulus of a test meal; that it is simple to carry out; and that it is relatively nontraumatic to the patient so it may be performed on children, elderly, or ill patients. The test requires the measurement of only a single trypsin level, and appears to distinguish the normal from abnormal pancreas though with the exceptions noted above. This distinction is probably nearly as accurate as that obtained by tests employing hormonal stimuli.

We wish to thank Professor D. N. Baron for helpful criticism and advice, and Miss E. Bateman for preparation of the Lundh test meals.

\section{References}

Cook, H. B., Lennard-Jones, J. E., Sherif, S. M., and Wiggins, H. S.
(1967). Measurement of tryptic activity in intestinal juice as a diagnostic test of pancreatic disease. Gut, 8, 408-414.

Dreiling, D. A., and Janowitz, H. D. (1962). The measurement of pancreatic secretory function. In The Exocrine Pancreas (Ciba으 Foundation Symposium edited by A. V.S. de Reuck and M. P. Cameron, pp. 225-258. Churchill, London.

Lundh, G. (1962). Pancreatic exocrine function in neoplastic and inflammatory disease: a simple and reliable new test. Gastro- $O$ enterology, 42, 275-280.

Lundh, G. (1965). Diagnostic investigations of the external pancreatic $\frac{\overline{\bar{D}}}{\overline{\mathrm{D}}}$ secretion. Proc. Congr. int. Soc. Surg., 21, 39-51.

Hummel, B. C. W. (1959). A modified spectrophotometric determina- $\vec{D}$ tion of chymotrypsin, trypsin, and thrombin. Canad. J. Biochem., 37, 1393-1399.

McCarthy, D. M., and Brown, P. (1969). Measurement of duodenal tryptic activity and ${ }^{75} \mathrm{Se}$-selenomethionine pancreatic scanning $\vec{O}$ compared as tests of pancreatic function. Gut, 10, 913-920.

Ventzke, L. E., Davidson, W. A., and Grossman, M. I. (1964). Diagnostic value of pancreatic enzymatic response to a test $\underset{\sigma}{\omega}$ meal. (Abstr.) Gastroenterology, 46, 765.

Youngs, G. R., Agnew, J. E., Levin, G. E., and Bouchier, I. A. D. 응 (1971). A comparative study of four tests of pancreatic function $\mathrm{N}$ in the diagnosis of pancreatic disease. (Abstr.) Quart. J. Med., G 40, 576-577.

Zieve, L., Mulford, B., and McHale, A. (1966). Secretion of pancreatic $\vec{N}$ enzymes. II. Comparative response following test meal or injection of secretin and pancreozymin. Amer. J. dig. Dis., 11, 685-694. 